\title{
Progression of liver pathology in patients undergoing the Fontan procedure: Chronic passive congestion, cardiac cirrhosis, hepatic adenoma, and hepatocellular carcinoma
}

Amir A. Ghaferi, BS, and Grover M. Hutchins, MD

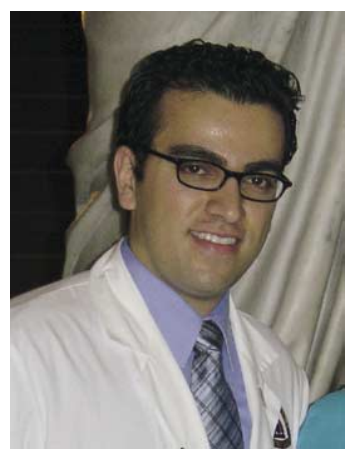

Mr Ghaferi
Background: Staged palliative surgical procedures have been an effective treatment of complex congenital heart defects. The Fontan procedure has been of particular benefit to infants with functional single-ventricle complexes but with the consequence of a sustained increase of right-sided venous pressure.

Methods: We reviewed the clinical and pathologic features of 9 autopsied patients having undergone the Fontan procedure, with special attention given to their liver pathology.

Results: The 9 patients died from a few hours to 18 years after the Fontan operation. Chronic passive congestion was seen in 7 patients, and 4 patients surviving 4 to 18 years also had cardiac cirrhosis. Hepatic adenoma in the setting of cardiac cirrhosis was found in a patient surviving for 9 years. One patient surviving for 18 years had hepatocellular carcinoma superimposed on cardiac cirrhosis. Rupture of the hepatoma in this case led to fatal hemorrhage.

Conclusion: The study shows that chronically increased hepatic venous pressure from the Fontan procedure might lead to chronic passive congestion, cardiac cirrhosis, hepatic adenoma, and hepatocellular carcinoma.

I n 1971, Fontan and Baudet ${ }^{1}$ reported on a highly effective palliative operation for infants born with tricuspid atresia. With improved management strategies of intensive care units, there has been a shift in focus in patients undergoing the Fontan procedure from survival to long-term morbidity and quality of life. ${ }^{2}$ There is still significant morbidity after the completion of these operations, including myocardial dysfunction, ${ }^{3,4}$ diminished exercise capacity, ${ }^{5}$ arrhythmias, ${ }^{6}$ proteinlosing enteropathy, ${ }^{7}$ thrombotic complications, ${ }^{8}$ somatic growth retardation, ${ }^{9}$ neoaortic valve root dilatation and insufficiency, ${ }^{10}$ and the possibility of suboptimal neurodevelopmental outcome. ${ }^{11}$ We have observed a 24-year-old patient at autopsy with tricuspid atresia who had undergone a Fontan operation at 6 years of age and experienced hepatocellular carcinoma (HCC), which had caused his death. This case prompted us to review our autopsy files for patients having undergone the Fontan procedure to assess the nature of their liver pathology.

\section{Materials and Methods}

The clinical and pathologic features of the 9 patients having undergone the Fontan procedure and autopsy examination of the liver pathology is shown in Table 1. The autopsies took place between 1983 and 2003. The index of autopsies performed at The Johns Hopkins Hospital was searched, and patients were included in the study who had liver histology available for review and who had a history of the Fontan procedure. We also examined each patient's records for the last recorded right atrial pressure before death.

We reviewed the liver histology, looking for 3 main pathologic features, namely chronic passive congestion (CPC), centrilobular necrosis (CLN), and cardiac cirrhosis 
TABLE 1. Clinical features of 9 patients having undergone the Fontan procedure autopsied at The Johns Hopkins Hospital

\begin{tabular}{|c|c|c|c|c|c|c|c|}
\hline $\begin{array}{l}\text { Patient } \\
\text { no. }\end{array}$ & $\begin{array}{l}\text { Age } \\
\text { (y) }\end{array}$ & Sex & $\begin{array}{l}\text { Autopsy } \\
\text { (y) }\end{array}$ & $\begin{array}{l}\text { Fontan } \\
\text { (time) }\end{array}$ & $\begin{array}{c}\text { Mean RA pressure } \\
(\mathrm{mm} \mathrm{Hg})\end{array}$ & Miscellaneous defects & Other procedures \\
\hline 1 & 18 & M & 1984 & Few hours & 5 & $\begin{array}{l}\text { Transposition of great vessels, } \\
\text { pulmonary valve atresia }\end{array}$ & Potts shunt \\
\hline 2 & 11 & M & 1983 & $1 \mathrm{~d}$ & 13.5 & $\begin{array}{l}\text { Transposition of great vessels, } \\
\text { large VSD, coarctation of } \\
\text { aorta }\end{array}$ & PA banding \\
\hline 3 & 1.66 & $\mathrm{~F}$ & 1988 & $2 d$ & 12.5 & $\begin{array}{l}\text { Tricuspid atresia, transposition } \\
\text { of the great vessels, } \\
\text { double-inlet left ventricle, } \\
\text { ASD, VSD }\end{array}$ & PA banding \\
\hline 4 & 6 & M & 2002 & $14 \mathrm{~d}$ & 11 & $\begin{array}{l}\text { Hypoplastic left heart, left } \\
\text { hemidiaphragmatic paralysis }\end{array}$ & $\begin{array}{l}\text { Left hemidiaphragm } \\
\text { plication, Glenn shunt, } \\
\text { atrial septectomy }\end{array}$ \\
\hline 5 & 3 & $\mathrm{~F}$ & 1997 & $1 \mathrm{y}$ & 19 & $\begin{array}{l}\text { Double-outlet right ventricle, } \\
\text { unbalanced AV canal } \\
\text { defect, coarctation of the } \\
\text { aorta }\end{array}$ & $\begin{array}{l}\text { Bidirectional Glenn } \\
\text { shunt, closure of } \\
\text { pulmonary artery, } \\
\text { repair of coarctation }\end{array}$ \\
\hline 6 & 10 & $\mathrm{~F}$ & 1986 & $4 y$ & 18 & $\begin{array}{l}\text { Tricuspid atresia, hypoplastic } \\
\text { right ventricle, ASD, VSD }\end{array}$ & BT shunt \\
\hline 7 & 14 & M & 1999 & $9 y$ & 8 (1989) & Tricuspid atresia, ASD, VSD & BT shunt, Glenn shunt \\
\hline 8 & 22 & M & 1994 & $10 y$ & Not available & $\begin{array}{l}\text { Transposition of the great } \\
\text { vessels, pulmonary stenosis, } \\
\text { large tricuspid valve } \\
\text { opening }\end{array}$ & BT shunt \\
\hline 9 & 24 & M & 2003 & $18 y$ & Not available & Tricuspid atresia, ASD, VSD & $\begin{array}{l}\text { PA banding, Glenn shunt, } \\
\text { ASD repair }\end{array}$ \\
\hline
\end{tabular}

$R A$, Right atrium; $V S D$, ventricular septal defect; $P A$, pulmonary artery; $A S D$, atrial septal defect; $B T$, Blalock-Taussig.

(CC; Table 2). The histologic features were graded on a semiquantitative scale ( 0 to $4+$ ), as previously described by Arcidi and colleagues. ${ }^{12}$ We identified CPC and CLN on the basis of histologic changes (Figure 1). The features used to establish the presence of CPC were atrophy of hepatic parenchymal cells, distention of sinusoids, and, in the severe grades, fibrosis in the centrilobular areas. The presence of CC was established on the basis of assessment of the level of centrilobular fibrosis with bridging fibrosis and the rearrangement of the lobular architec- ture (see Figure 3, B). The presence of CLN was defined as necrosis of centrilobular hepatic parenchymal cells. Possible neoplastic nodules were studied with immunohistochemical stains for Hep Par1 and p-carcinoembryonic antigen.

\section{Results}

The 9 patients having undergone the Fontan procedure autopsied at Hopkins were examined for the nature of their

TABLE 2. Pathologic features of 9 patients having undergone the Fontan procedure autopsied at The Johns Hopkins Hospital

\begin{tabular}{cccccccc}
\hline Patient no. & Age $(\mathbf{y})$ & Sex & (time postoperatively) & CPC & CLN & CC & Cause of death \\
\hline 1 & 18 & M & Few hours & $1+$ & 0 & No & Hemothorax \\
2 & 11 & M & $1 \mathrm{~d}$ & 0 & $2+$ & No & Severe subaortic stenosis \\
3 & 1.66 & $\mathrm{~F}$ & $2 \mathrm{~d}$ & 0 & $3 / 4+$ & No & Congestive heart failure \\
4 & 6 & $\mathrm{M}$ & $14 \mathrm{~d}$ & $2+$ & $4+$ & No & Multiple organ failure \\
5 & 3 & $\mathrm{~F}$ & $1 \mathrm{y}$ & $3+$ & 0 & No & Pseudomonas sepsis \\
6 & 10 & $\mathrm{~F}$ & $9 \mathrm{y}$ & $4+$ & 0 & Yes & Fungemia \\
7 & 14 & $\mathrm{M}$ & $10 \mathrm{y}$ & $4+$ & $2+$ & Yes & Pulmonary embolus \\
8 & 22 & $\mathrm{M}$ & $18 \mathrm{y}$ & $4+$ & 0 & Yes & Bacterial sepsis \\
9 & 24 & $\mathrm{M}$ & $4+$ & $4+$ & Yes & Hemoperitoneum
\end{tabular}

$C P C$, Chronic passive congestion; $C L N$, centrilobular necrosis; $C C$, cardiac cirrhosis. 


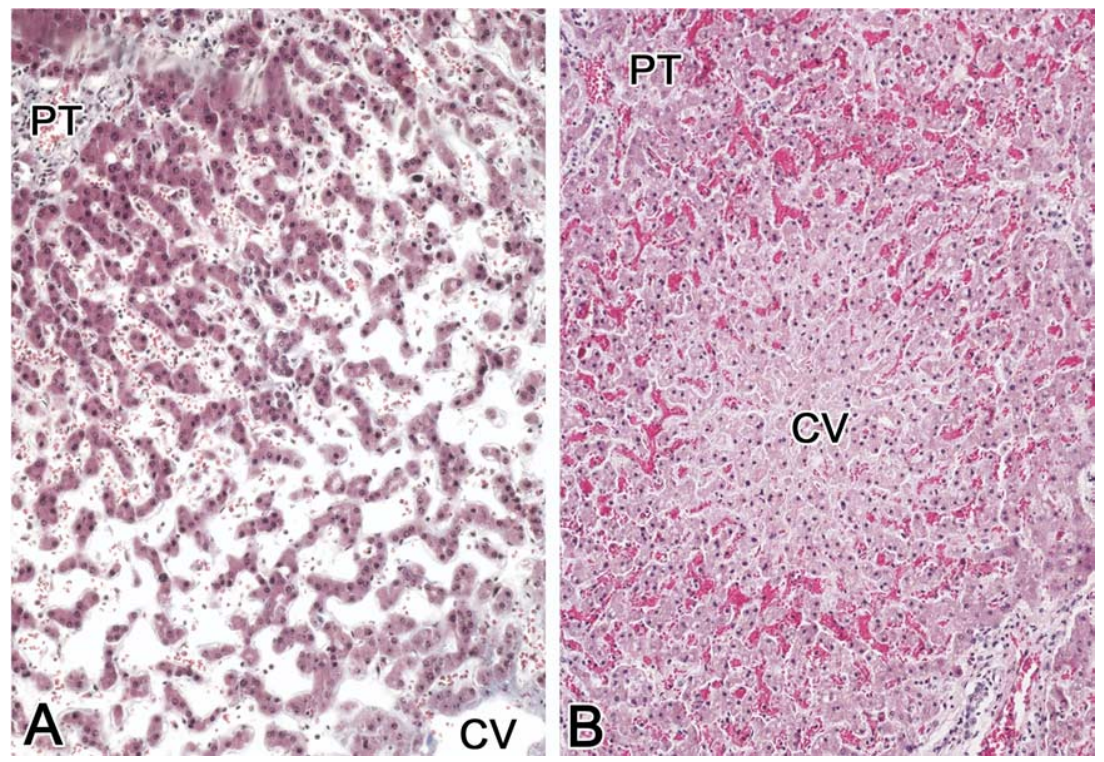

Figure 1. Comparison of CPC and CLN of the liver. A, In CPC the liver tissue is preserved around the portal triad. The parenchyma around the central vein has atrophy of the liver cell cords, distention of the sinusoids, and enlargement of the space between the liver cell cord and the reticular framework that supports the Kupfer cells (space of Disse). The pathologic features of CPC arise from increased pressure in the hepatic venous drainage, which is most commonly caused by right-sided congestive heart failure. B, CLN of the liver is caused by inadequate perfusion of the liver lobule by portal vein blood flow, usually caused by shock. Reflecting the severity of shock, there is a gradient of necrosis extending from the central vein toward the portal triads. A ring of liver parenchyma around the portal triad is almost always preserved, even with very severe shock, as a result of continuing hepatic artery perfusion of that region of the lobule. (Both hematoxylin and eosin; original magnification $40 \times$.) CV, Central vein; $P T$, portal triad.
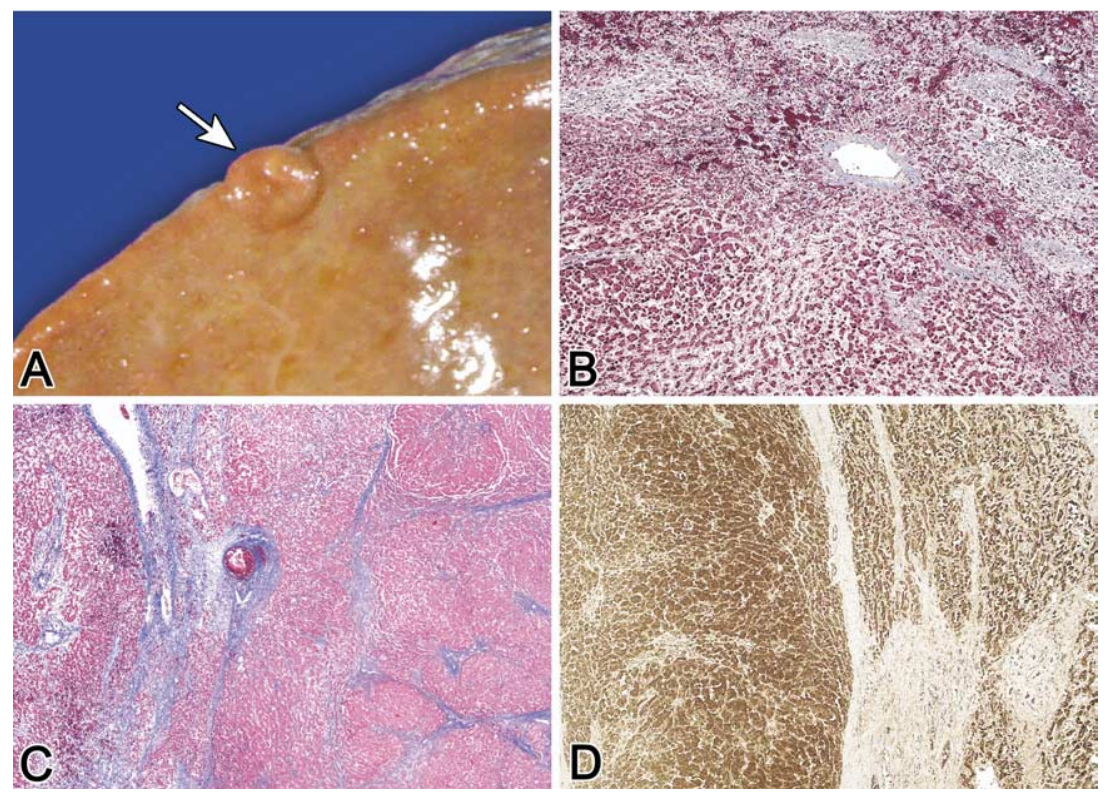

Figure 2. Case 7. A, A $1.5-\mathrm{cm}$ hepatic adenoma protrudes from the margin of the left lobe of the liver. B, The liver parenchyma has severe distortion of lobular architecture typical of CC (Hematoxylin and eosin, original magnification $20 \times$ ). C, The adenoma is on the right, and the compressed nonneoplastic liver parenchyma is on the left (Masson trichrome, original magnification $10 \times$ ). D, An immunohistochemical stain with a hepatocyte marker shows more intense staining in the adenoma on the left compared with the compressed liver parenchyma on the right (HepPar 1, original magnification $20 \times$ ). 


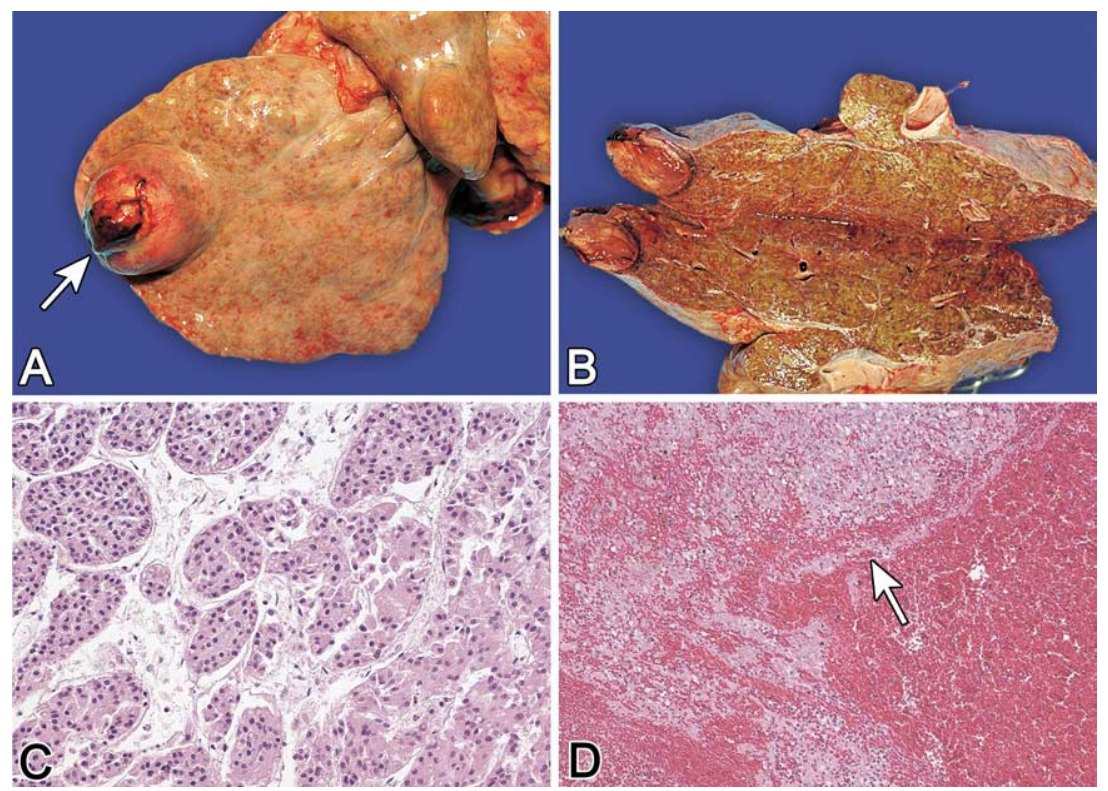

Figure 3. Case 9. A, View of the posterior-inferior aspect of the left lobe of the liver showing a 4-cm HCC protruding through the capsule with hemorrhage on its surface (arrow). There is a nodular cirrhotic appearance to the remainder of the liver. B, Section through the liver with the HCC at the left and prominent intrahepatic nodularity and fibrosis caused by CC. C, Histologic appearance of the HCC (Hematoxylin and eosin, original magnification $100 \times$ ). D, Area of the spontaneously disrupted capsule (arrow) with extruded HCC tissue and blood.

hepatic pathology. The patients ranged in age (at time of autopsy) from 20 months to 24 years. The findings are summarized in Tables 1 and 2.

Of the 9 cases reviewed, there were 4 cases in which the histologic diagnosis of $\mathrm{CC}$ was made by the criteria described above (patients 6-9). By definition and examination, those 4 patients had $4+$ ratings of $\mathrm{CPC}$, whereas only 2 patients (patients 7 and 9) showed any evidence of CLN. Their analysis accurately depicts the physiologic state in the patients described here.

The hepatic changes related to CPC observed in this series of 9 patients correlates nearly directly with the amount of time each patient lived with the Fontan procedure. Likewise, a correlate can be drawn between the right atrial pressures and the extent of CPC, as depicted in Table 2 . In addition, 2 of the 3 patients with the longest survivals were found to have neoplastic transformation associated with their CC.

Patient 7 died at the age of 14 years and had lived for 9 years after the Fontan procedure. The gross and histologic features of the hepatic nodule found at autopsy are consistent with a hepatic adenoma (Figure 2). The immunohistochemical staining supported this diagnosis.

Patient 9 had a 4 -cm mass, with overlying hemorrhage protruding from the posteroinferior aspect of the left lobe of the heavily cirrhotic liver. Histologic examination revealed
HCC with thickened hepatic cords and nests of hepatocytes wrapped in endothelial cells. The diagnosis of HCC was confirmed by using Hep Par1 and p-carcinoembryonic antigen staining. The specificity and sensitivity of these stains in confirming $\mathrm{HCC}$ diagnoses are $90 \%$ and $80 \%$ and $100 \%$ and $50 \%$ to $90 \%$, respectively. Trichrome staining was performed to further reveal the level of fibrosis and the presence of CC (Figure 3). Other potential causes of cirrhosis and thus risk for HCC were examined and ruled out on the basis of the patient's clinical history and special immunohistochemical staining techniques on postmortem tissue samples. These potential causes included alcoholic liver disease, chronic hepatitis $\mathrm{C}$ virus infection, primary biliary cirrhosis, primary sclerosing cholangitis, autoimmune hepatitis, chronic hepatitis B virus infection, hereditary hemochromatosis, Wilson disease, and $\alpha_{1}$-antitrypsin deficiency.

\section{Discussion}

Right-sided heart failure results in transmission of increased central venous pressure directly to the liver through the inferior vena cava and the hepatic veins. The clinical presentation of congestive hepatopathy is generally masked by the customary symptoms and signs of right-sided heart failure. There is no evidence that the presence of congestive liver disease worsens the prognosis of patients with heart 
failure, whose mortality rates are dominated by the severity of the cardiac disease.

Hepatic CPC and CLN are commonly encountered at autopsy and imply a circulatory abnormality. CPC is usually a consequence of right-sided heart failure, whereas CLN is usually a consequence of severe hypotension or shock. Severe prolonged CPC can eventually lead to the development of CC, which, histologically, in the early stages of the disease process, exhibits a distinguishing reverse lobulation pattern in which fibrous septa form bridges between central veins. In long-standing or severe cases, the cell loss and collapse of normal architecture might spread to incorporate some portal tracts. However, there are rarely portal inflammatory cells or bile ductular proliferation, which helps distinguish CC from the cirrhoses more commonly encountered in adults. ${ }^{13}$ Its incidence is unknown, but the most frequent causes include ischemic heart disease (31\%), cardiomyopathy (23\%), valvular heart disease $(23 \%)$, primary lung disease $(15 \%)$, and pericardial disease $(8 \%)$. The clinical diagnosis of the condition is difficult because there have been no conclusive studies correlating liver function tests or other serum markers to the disease process. ${ }^{14}$

In our opinion the relationship between increased rightsided pressures and CC is now clear. Lemmer and colleagues ${ }^{15}$ reported a case of a 15-year-old girl who, on postmortem examination, had evidence of CC 5 years after a modified Fontan procedure for tricuspid atresia. The case report is very similar to that of the patient described in our article, who went on to have HCC (patient 9). Mean right atrial pressures after successful modified Fontan procedures are usually in the range of 8 to $20 \mathrm{~mm} \mathrm{Hg}$. The patients described in our series clearly fall within this range, and those with marked $\mathrm{CC}$ are in the upper echelon of this range. Previous studies have shown that increased venous pressures have been shown to be associated with increased morbidity and mortality in patients undergoing the Fontan procedure ${ }^{16}$ In 1990, Ho and associates ${ }^{17}$ presented a case report of a 50-year-old man who had lived with constrictive pericarditis since the age of 23 years. He experienced long-standing hepatic venous congestion. On routine examination, he was found to have a firm hepatic mass in the right lobe of the liver and, after various studies, was found to have an enlarged liver with macronodular cirrhosis. He then underwent a laparotomy and wedge resection of the mass, which revealed HCC. He was, like our patient 9, found to have no other potential underlying causes for his liver cirrhosis or HCC, other than chronically increased right-sided pressures. The authors therefore concluded that this patient was the first reported case of an HCC associated with CC.
We now report what we believe to be the second such reported case but in a patient population that can be monitored closely for known increase of right-sided pressures. Given observations presented here, patients who undergo the Fontan procedure or similar operations must be carefully followed for the development of chronic liver disease, which could ultimately result in HCC and a fatal outcome.

\section{References}

1. Fontan F, Baudet E. Surgical repair of tricuspid atresia. Thorax. 1971;26:240-8.

2. Marino BS. Outcomes after the Fontan procedure. Curr Opin Pediatr. 2002;14:620-6.

3. Cheung YF, Penny DJ, Redington AN. Serial assessment of left ventricular diastolic function after Fontan procedure. Heart. 2000;83:420-4.

4. Sensaki H, Masutani S, Kobayashi J, Kobayashi T, Sasaki N, Asano H, et al. Ventricular afterload and ventricular work in Fontan circulation: comparison with normal two-ventricle circulation and single-ventricle circulation with Blalock-Taussig shunts. Circulation. 2002;105:2885-92.

5. Fredriksen PM, Therrien J, Veldtman G, Warsi MA, Liu P, Siu S, et al. Lung function and aerobic capacity in adult patients following modified Fontan procedure. Heart. 2001;85:295-9.

6. Ovroutski S, Dahnert I, Alexi-Meskishvili V, Nurnberg JH, Hetzer R, Lange PE. Preliminary analysis of arrhythmias after the Fontan operation with extracardiac conduit compared with intra-atrial lateral tunnel. Thorac Cardiovasc Surg. 2001;49:334-7.

7. Mertens L, Hagler DJ, Sauer U, Somerville J, Gewillig M. Proteinlosing enteropathy after the Fontan operation: an international multicenter study. PLE Study Group. J Thorac Cardiovasc Surg. 1998;115: 1063-73.

8. Balling G, Vogt M, Kaemmerer H, Eicken A, Meisner H, Hess J. Intracardiac thrombus formation after the Fontan operation. $J$ Thorac Cardiovasc Surg. 2000;119:745-52.

9. Cohen MI, Bush DM, Ferry RJ Jr, Spray TL, Moshang T Jr, Wernovsky G, et al. Somatic growth failure after the Fontan operation. Cardiol Young. 2000;10:447-57.

10. Cohen MS, Marino BS, McElhinney DB, Robbers-Visser D, van der Woerd W, Gaynor JW, et al. Neo-aortic root dilation and valve regurgitation up to 21 years after staged reconstruction for hypoplastic left heart syndrome. J Am Coll Cardiol. 2000;42:533-40.

11. Wernovsky G, Stiles KM, Gauvreau K, Gentles TL, duPlessis AJ, Bellinger DC, et al. Cognitive development after the Fontan operation. Circulation. 2000;102:883-9.

12. Arcidi JM Jr, Moore GW, Hutchins GM. Hepatic morphology in cardiac dysfunction: a clinicopathologic study of 1000 subjects at autopsy. Am J Pathol. 1981;104:159-66.

13. Schafer DF, Sorrell MF. Vascular diseases of the liver. In: Feldman M, Friedman LS, Sleisenger MH, editors. Sleisenger and Fordtran's gastrointestinal and liver disease. 7th ed. Philadelphia: Saunders; 2002. p. 1364-71.

14. Dunn GD, Hayes P, Breen KJ, Schenker S. The liver in congestive heart failure: a review. Am J Med Sci. 1973;265:174-89.

15. Lemmer JH, Coran AG, Behrendt DM, Heidelberger KP, Stern AM. Liver fibrosis (cardiac cirrhosis) five years after modified Fontan operation for tricuspid atresia. J Thorac Cardiovasc Surg. 1983;86: 757-60.

16. Sanders SP, Wright GB, Keane JF, Norwood WI, Castaneda AR. Clinical and hemodynamic results of the Fontan operation for tricuspid atresia. Am J Cardiol. 1982;49:1733-40.

17. Ho SS, Brown R, Fitzgibbon B. Hepatocellular carcinoma with cardiac cirrhosis. Med J Aust. 1990;152:553-4. 